\title{
The impact of student timetables and commuting on student satisfaction
}

\author{
Nigel Page ${ }^{1}$, Gary Forster-Wilkins ${ }^{1}, \&$ Mark Bonetzky ${ }^{2}$ \\ School of Life Sciences, Pharmacy and Chemistry ${ }^{1}$; Academic Services (Education) ${ }^{2}$; Penrhyn Road, \\ Kingston University London, Kingston-upon-Thames, London, UK.
}

*Corresponding author: n.page@kingston.ac.uk

Keywords: Timetabling; Commuting; Inclusion; Support; Post-COVID-19.

\begin{abstract}
Widening participation has encouraged students from a diverse range of backgrounds into university with more students commuting (many being Black and Minority Ethnic, BME). Since timetabling forms a major way by which students identify and interact with their learning environment understanding its influence is important. This project aimed to identify the experiences of students with their timetables using questionnaires and focus groups to determine perceptions and relationship to travel to university by ethnicity, gender, age and level of study. Five hundred and fifty students participated across levels 4 to 6 at Kingston University. There was a strong negative correlation between travel time and 'the timetable works efficiently for me' (Question 16, National Student Survey). Students from ethnic backgrounds on average were found to travel double the distances of their White counterparts to get to university. In addition, timetable satisfaction was also reflected in the modes of transport used and in perceptions of expected timetabled hours (i.e., whether too many or too few hours scheduled) based on travel times. We identified a number of inclusive priorities to help improve the timetable for student groups including having later starts to days and one guaranteed day free per week. In addition, the COVID-19 world has temporarily reduced the need for most students to commute and can be regarded as a positive disruptor for future commuting students. Certainly, it will be important to find a new balance in applying the identified priorities
\end{abstract}

and the realised alternative COVID-19 teaching practices for creating more inclusive, flexible and blended learning environments to achieve the ultimate student-centred timetable.

\section{Introduction}

Key to any university strategy is the development of inclusive mechanisms to support all who can benefit from a higher education, regardless of background, so that they can participate fully and complete it successfully. Nonetheless, the rapidly evolving higher education (HE) landscape creates challenges that need to consider a significantly more diverse student body, whereby the ability to fully participate becomes an important factor linked to student retention, progression, attainment and ultimately employability prospects (Webb et al., 2017).

Today, many students commute from the communities they live (many being Black and Minority Ethnic, BME), potentially hindering their ability to fully participate (Southall et al., 2016). This is particularly true for those students attending HE establishments that are post-1992 and those in major cities such as London (Donnelly \& Gamsu, 2018). Furthermore, there is evidence to support a 'London effect' that has been linked to lower student satisfaction (such as measured by the National Student Survey), poorer continuation and completion rates, along with weaker senses of institutional belonging (BuckleyIrvine, 2017; Pokorny et al., 2016). MorganTamosunas (2012) suggested that for 
universities in the capital it is the fact that many students live at home with longer travel times that impacts on their experience.

Certainly, within the STEM subject areas at Kingston University London, we have some of the highest numbers of commuting students (often over two thirds on some courses). Compounding this, is the requirement to deliver a greater number of timetabled activities such as practical sessions and workshops, which necessitates more complicated logistics in coordinating these activities. These factors can introduce numerous constraints in producing efficient and effective timetables along with creating perceived disparities in course delivery between different subject areas.

Since the timetable is a major way by which students identify and interact with their learning environment, both in time and space, this can be ultimately reflected in the student experience and levels of engagement (The Quality Assurance Agency for Higher Education, 2014; Thomas \& Jones (2017). Therefore, ensuring an efficient timetable that is inclusive and student-centred is fundamental to any higher education strategy and especially for those with higher numbers of commuting students. In this project, we have aimed to gain a greater understanding of our students (from those of our School of Life Sciences, Pharmacy and Chemistry) by exploring their opinions on their timetables and commuting habits. Overall, our intention is to develop and implement more inclusive learning and teaching strategies that reflects our student needs better.

This paper is structured into a methods section, followed by a review of the results and then a discussion, which provides a detailed analysis of the results with the overall outcomes summarised.

\section{Methods}

An ethically approved (Kingston University Centre for Higher Education Research and Practice Ethics Panel) survey was developed that included the fundamental research questions alongside demographic data (such as ethnicity, age and gender). Core questions were designed to ascertain information on student timetable satisfaction and expectations, the barriers and enablers in timetabling and the impact of journey times and mode of transport. Distances and journey times were calculated using term-time postcode addresses and the Google mapping tools to calculate the straight-line distance to the central university campus postcode. The Google direction tool was used to confirm travel times against student stated travel modes. Open text boxes were also included in the questionnaire to collect additional qualitative responses. The cohort comprised undergraduate students at level 4 to 6 , who were studying a range of different courses (including biological sciences, biochemistry, pharmacology, biomedical science, nutrition, forensic science, sports science, chemistry, and pharmaceutical science) within our School of Life Sciences, Pharmacy and Chemistry.

Surveys were anonymous and numerical data was entered, extracted and managed using Excel pivot tables, where the outputs were tabulated or displayed graphically. Parametric data was analysed by independent samples ttests for statistical significance and nonparametric data by chi square tests to identify differences in responses between groups. A significance level of $p<0.05$ was used in all tests.

To support the quantitative findings, a focus group was organised to generate qualitative data. A total of 12 participants from both BME and White backgrounds participated. Respondents attended for a one-hour session. Participants were asked to respond to a list of pre-designed questions by writing their thoughts on post-it notes and placing them in the middle of the table. The questions were then reiterated and discussed as a group, with the main themes being recorded by a notetaker. At the end of the session, post-it notes were collected with the permission of the participants and used for later reflection along with the notes taken during the group discussion.

\section{Results}

\section{Respondent Characteristics}

A total of 550 undergraduate students completed the survey from the School of Life Sciences, Pharmacy and Chemistry across levels 4 to 6 . The response rate represented 
around $37.1 \%$ of all eligible students being $30 \%, 39.5 \%$ and $45.5 \%$ of respondents from levels 4 to 6 , respectively. Of the collected surveys, 11 were not analysed owing to the participants not declaring either their ethnicity or gender. The final data set consisted of 539 surveys. $65.5 \%(n=353)$ of these students came from BME backgrounds and $34.5 \%(n=$ 186) were recorded as being from White ethnic backgrounds. This was comparable to the ethnicity constitution of the general Kingston University population (BME $64.6 \%$ vs White $35.4 \%$ ). Nonetheless, from this study and from comparison with existing ethnicity data, distinct and consistent ethnic profiles were found on each of our different courses. The percentages of BME students on the different courses from this study varied: biochemistry $(60 \%)$, biological science (51.5\%), biomedical science $(84.5 \%)$, forensic science $(46.5 \%)$, chemistry $(57 \%)$, nutrition $(46.4 \%)$, pharmaceutical science $(73.3 \%)$, pharmacology $(84 \%)$ and sports science $(44.4 \%)$. Our two largest courses, biomedical science and pharmaceutical science with 758 registered students between them had the highest percentage of BME students. Across all respondents, BME males $(23.1 \%)$ were more prevalent than White males $(15.1 \%)$ but overall, female BME students were the most common group $(42.3 \%)$ with White females (19.6\%). Compared with the expected gender demographic breakdown for the School as a whole, the study included a slightly higher representation of males $(38.6 \%$ vs $33.7 \%$, respectively) and for females a lower-thanexpected value $(61.4 \%$ vs $66.1 \%$, respectively). Most student respondents were aged 18 to $21(68.9 \%)$ with a lower percentage of those over $21(31.1 \%)$. The proportion of younger and older students who participated was similar to that expected for the School (age 18 to $21,68.9 \%$ vs $70.2 \%$ over 21 ). Based on journey times to university $52.8 \%$ of students indicated journey times of 30 minutes or less, with $47.1 \%$ indicating journey times of more than 30 minutes.

\section{Timetable satisfaction and expectations}

Participants were asked to think about the statement the timetable works efficiently for me', which also corresponds to question 16 of the National Student Survey and to indicate their response based on a Likert scale from 'definitely agree' to 'definitely disagree'.
Overall, there was a greater percentage of White students who selected 'definitely or mostly agree' $(68.5 \%)$ compared to BME students $(62.1 \%)$, however, this was not statistically significant $\left(\chi^{2}, 3.1, d f=2, p=\right.$ $0.20)$. We also reviewed the effect of gender $\left(\chi^{2}, 0.35, d f=2, p=0.83\right)$ and the effect of age between 18 to 21 and over $\left(\chi^{2}, 0.29, d f=\right.$ $2, p=0.86)$. No demographic factors were found to be significant in determining general timetable satisfaction. However, there was a significant difference in timetable satisfaction between levels, where level 4 students appeared the most satisfied $(71.5 \%)$ and level $5(57.8 \%)$ and $6(58.7 \%)$ much lower $\left(\chi^{2}, 9.36, d f=2, p=0.009\right)$.

Respondents were asked to consider in a typical week how many timetabled hours they had on their course and to compare this to their expectations (from 'far too much' to 'far too little'). Overall males, BME and White estimated 13.54 hours (SD $\pm 4.8 \mathrm{hrs}$ ) and 13.57 hours (SD $\pm 4.3 \mathrm{hrs}$ ), respectively. For females, BME and White estimated 12.7 hours (SD $\pm 5.0 \mathrm{hrs}$ ) and 12.9 hours (SD $\pm 4.5 \mathrm{hrs}$ ), respectively. There was an indication, males perceived their timetable as containing slightly more hours than females but this difference in reality was small at 0.75 hours; and not significant using one-way analysis of variance (ANOVA) (F-statistic value $=0.88, p=0.44$ ) for both ethnicity and gender. An analysis of the impact of age showed 18 to 21 olds perceived they had on average 12.81 (SD \pm 4.53 ) timetabled contact hours and for those over 21 old, 13.81 (SD \pm 5.1 ) hours. This difference was significant when using a t-test for two independent means $(p=0.045)$.

In terms of timetabled hours meeting expectations, $69.3 \%$ BME students said they did match 'as expected' compared to $76.4 \%$ White students, which was not a significant difference. Around a fifth of both BME and White students similarly stated the number of contact hours were 'too little' (lower than expected), $19.9 \%$ and $20.2 \%$, respectively. This difference was independent of ethnicity, gender and level of study. However, when dissecting for journey times, there was a significant difference, $23.8 \%$ of students with journey times between 0 to 30 minutes indicating lower than expected timetabled 


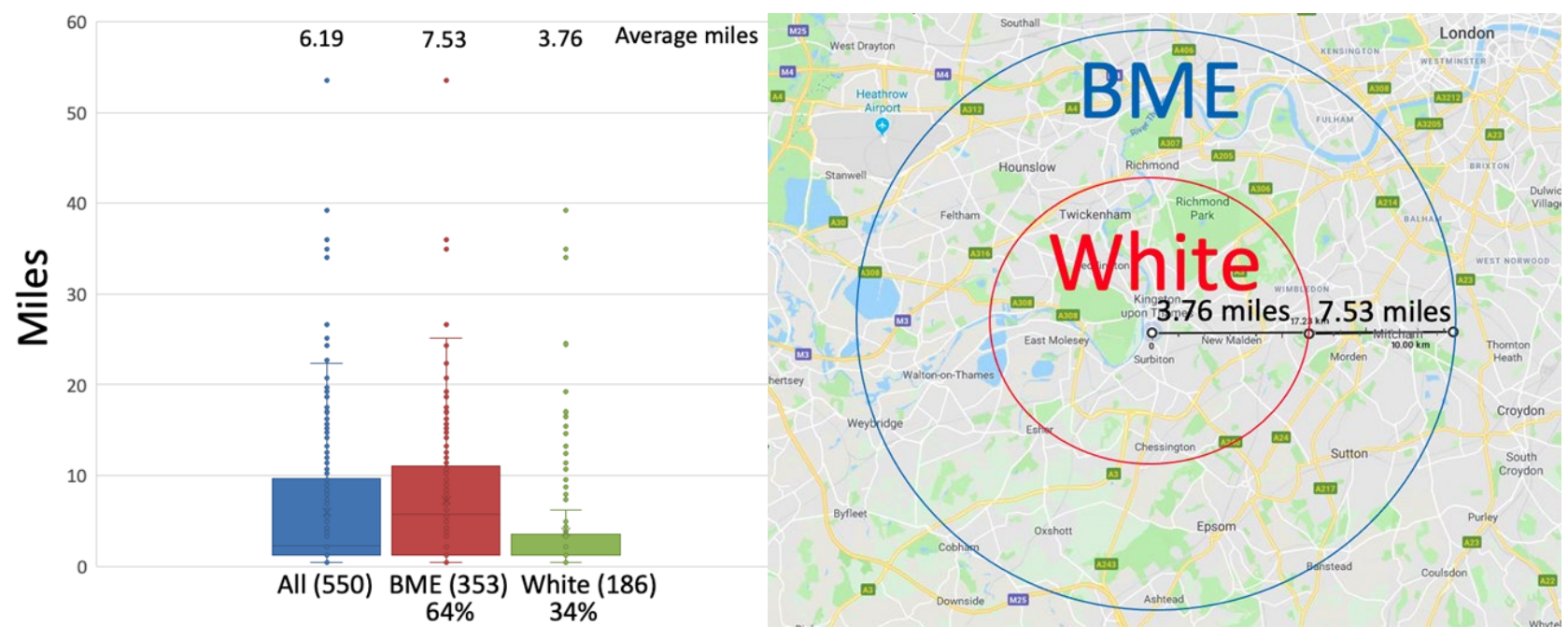

Figure 1 (Left) Graphical box and whisker plot and (right) mapped comparisons of student travel distances to Kingston University by ethnicity (Map data @2020 Google).

hours compared to $15.3 \%$ of students with journey times over 30 minutes $\left(\chi^{2}, 61.5, d f=\right.$ $4, p=0.0)$. Students were less likely to state their timetabled hours were 'too much' (more than expected). However, from those students, who were more likely to state this, these were BME students $(10.8 \%)$ compared to White $(3.4 \%)$ students. This result was statistically significant for ethnicity $\left(\chi^{2}, 8.68, d f=2, p=\right.$ 0.013 ) but was found to be independent of gender and age. Further analysis linking journey times to 'too much' hours demonstrated a significant difference for students with journey times over 90 minutes (20.2\% indicating too much) compared to those with journeys under 30 minutes $(5.9 \%$ indicating too much $)\left(\chi^{2}, 18.4, d f=2, p=\right.$ 0.0001 ). The group of students (scoring $79.6 \%$, $n=117$ ) who were most satisfied with having an expected number of timetabled hours were those with journey times between 30 to 90 minutes.

Following on, we asked students to report on the proportion of timetabled hours they had attended (from $0-25 \%, 25-50 \%, 50-75 \%$ to $75-100 \%)$. Students from both BME and White groups, $85 \%$ and $86.6 \%$ respectively, reported attending $75-100 \%$ of their timetabled hours. There was no statistical difference found between the self-reporting BME and White students $\left(\chi^{2}, 0.098, d f=3, p=0.99\right)$. Selfreporting was equitable between BME males and females (both $85.5 \%$ and $84.8 \%$ respectively), however, there were significant differences between White males and females $(68.4 \%$ and $93.3 \%$ respectively indicating $75-100 \%$ attendance $)\left(\chi^{2}, 14.84, d f=3, p=\right.$ $0.00059)$. A greater number of White males $(26.3 \%)$ instead claimed to be attending only $50-75 \%$ of their timetabled activities vs $5.8 \%$ White female.

\section{Impact of journey times and mode of transport on timetable satisfaction}

To measure the impact of ethnicity, gender, and age on journey times and mode of transport, we collected data from the first part of each student's postcode to determine the district they lived using Google mapping tools to calculate approximate distances and journey times with those modes of transport stated by students.

The average distance travelled by students to get to university was found to be 6.18 miles. Separating the mean distances travelled between those of BME and White students demonstrated a significant difference ( $p=$ 0.0001 ) of 7.53 miles for BME students and 3.76 miles for White students (Figure 1). These distances were also reflected in the calculated mean travel times of 55.3 mins and 33.0 mins for BME and White students, respectively ( $p=$ 0.0001 ). While there were slight differences in the mean travel times between BME males and females (51.1 mins and 57.5 mins, $p=0.13$, respectively,) and White males and females 
The impact of student timetables and commuting on student satisfaction

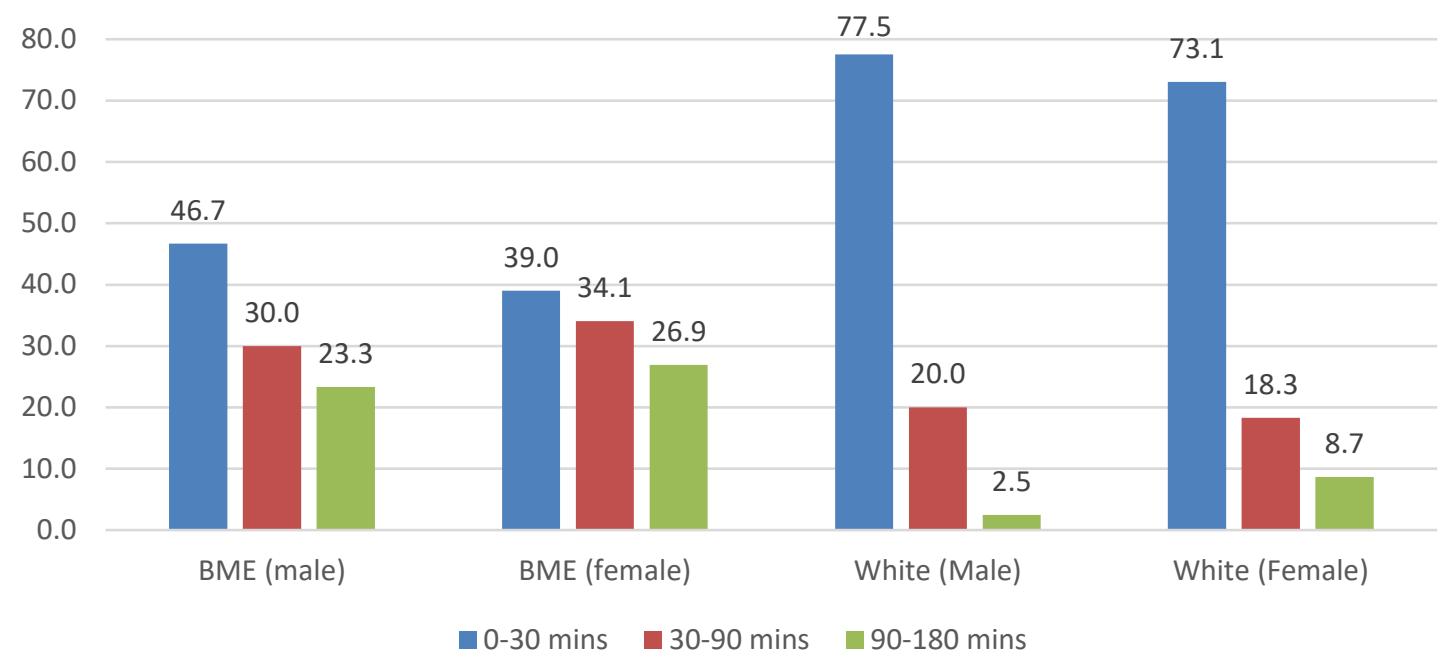

Figure 2 Comparison of travel times to university by ethnicity and gender. Data labels represent percentage of students in each group.

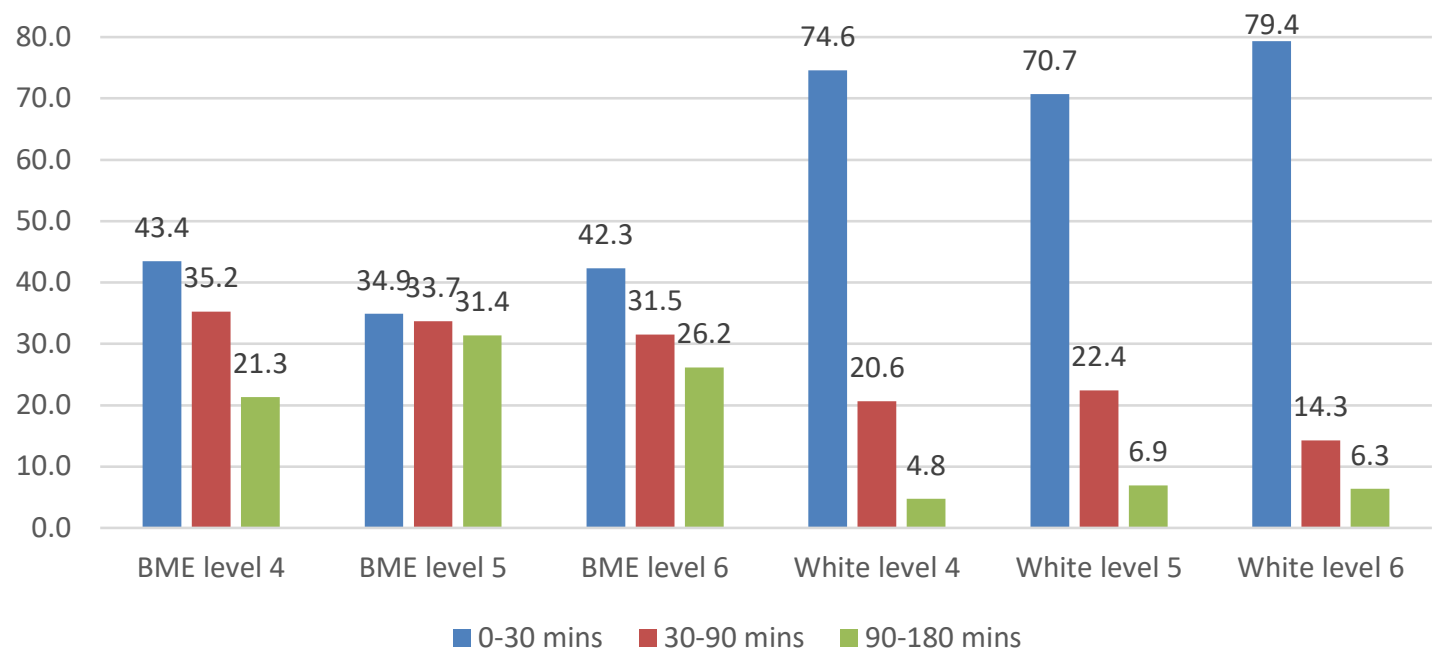

Figure 3 Comparison of travel times by ethnicity and study level. Data labels represent percentage of students in each group.

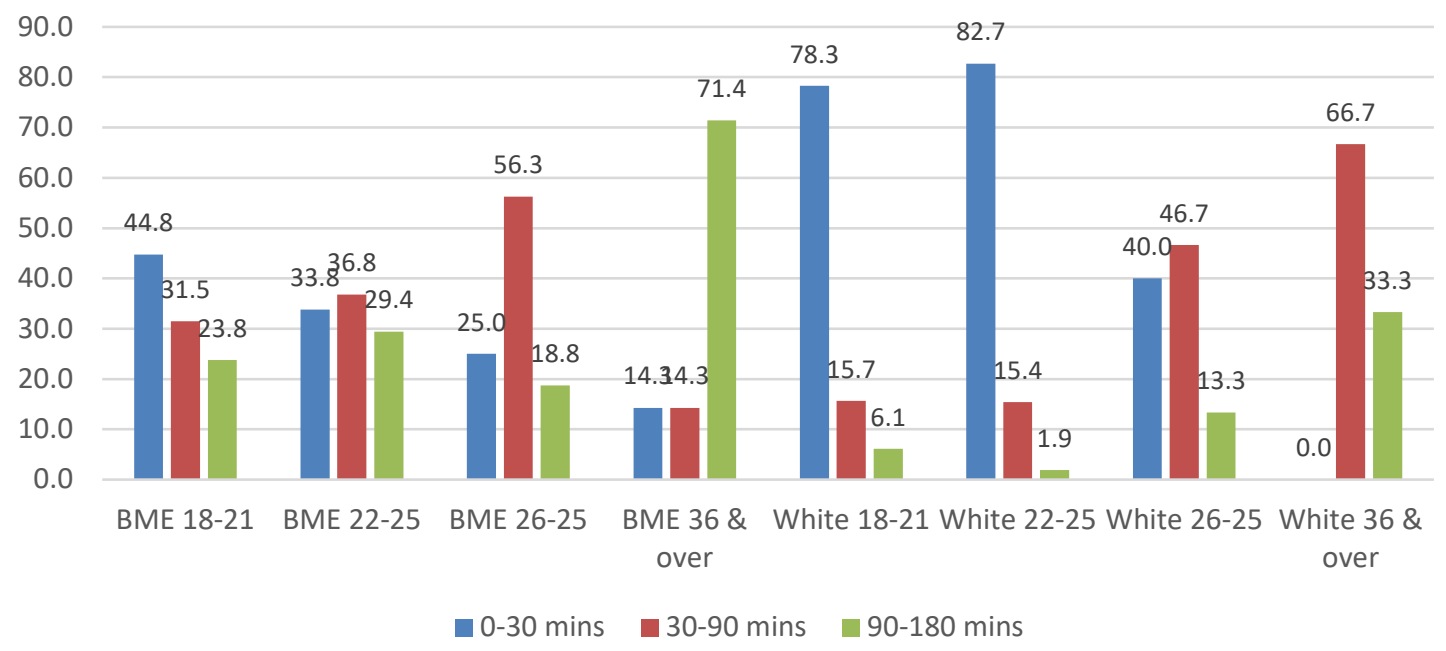

Figure 4 Comparison of travel times to university by ethnicity and age groups. Data labels represent percentage of students in each group. 


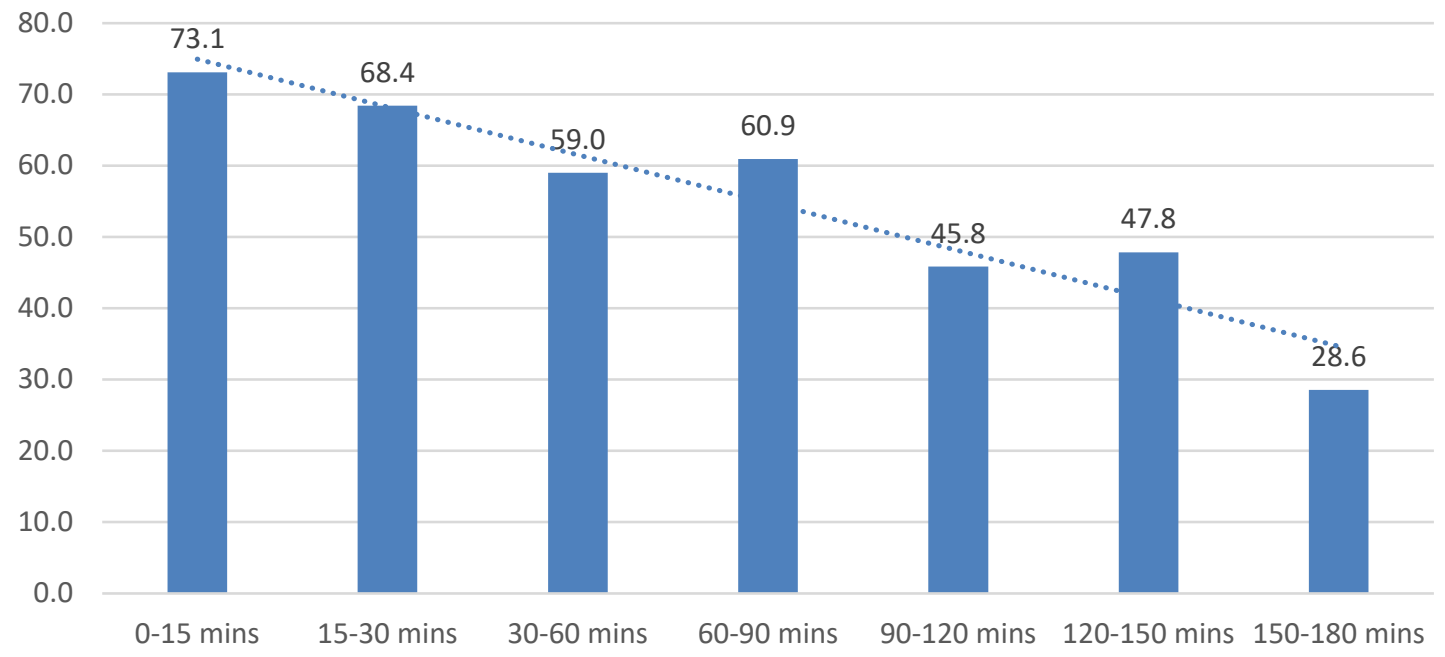

Figure 5 Impact of travel time on 'the timetable works efficiently for me'. Data labels represent percentage of student satisfaction.

(33.4 mins and 32.7 mins, $p=0.18$, respectively), these were not significant.

To gauge the impact of ethnicity and gender on travel times to university, we plotted a comparison of the percentage of BME and White students (male and female) against travel times of 0-30, 30-90, and 90-180 minutes (Figure 2). This showed significant differences $\left(\chi^{2}, 60.59, d f=6, p=0.0\right)$ in travel times between BME and White students with the majority of White (male $77.5 \%$ and female $73.1 \%$ ) students living within 0 to 30 minutes from the university compared to BME (male $46.7 \%$ and female $39 \%$ ) students. No significant gender differences were found between BME males and females $(p=0.39)$, and White males and females $(p=0.21)$ related to travel times.

To determine if travel patterns were related to choices made at different levels of study, we plotted the percentage of BME and White students studying at each level (4 to 6) against travel times (0-30, 30-90, and 90-180 minutes) (Figure 3). Again, this demonstrated significant differences $\left(\chi^{2}, 64.97, d f=10, p=0.0\right)$

between BME students and White students and also indicated that travel patterns of BME and White students, once established tended to differ very little between levels and ethnic groups. When we compared the ethnic differences (BME vs White) in travel time against student ages, we found these to be significant $\left(\chi^{2}, 67.16, d f=6, p=0.0\right)$ within the age ranges 18 to 21 , and 22 to 25 years old. Yet, for age groups, over the age of 25, we found there to be no significant difference $\left(\chi^{2}, 11.0, d f=6, p=0.088\right)$, where both mature BME and White students tended to have longer travel times to university (Figure 4).

To establish if there was a correlation between 'the timetable works efficiently for me' (Q16 of the NSS) and student travel time to university, we plotted student satisfaction ('definitely or mostly agree' percentages) against travel times (Figure 5). This demonstrated a strong negative correlation between student timetable satisfaction and travel time, which was significant when comparing BME vs White students $\left(\chi^{2}, 35.42, d f=2, p=0.0001\right)$ but was not significant for gender $\left(\chi^{2}, 3.55, d f=\right.$ $2, p=0.169)$ or student age $\left(\chi^{2}, 1.83, d f=\right.$ $2, p=0.40)$.

Travel times or distances also affected student's mode of transport to university. White students $(72 \%$ White vs $33 \%$ BME) were more likely to walk, cycle or use the university bus whilst conversely BME students relied much more on public transport (67\% BME vs $28 \%$ White) $\left(\chi^{2}, 65.52, d f=1, p=0.0\right)$. The modes of transport used by students in this study were ranked from walking $(31 \%)$, train or tube $(29.9 \%)$, bus public $(17.4 \%)$, motorcycle or car $(9.7 \%)$, university bus $(9 \%)$ to cycling $(2.9 \%)$. Students who used the university bus or walked had the greatest satisfaction rates for 

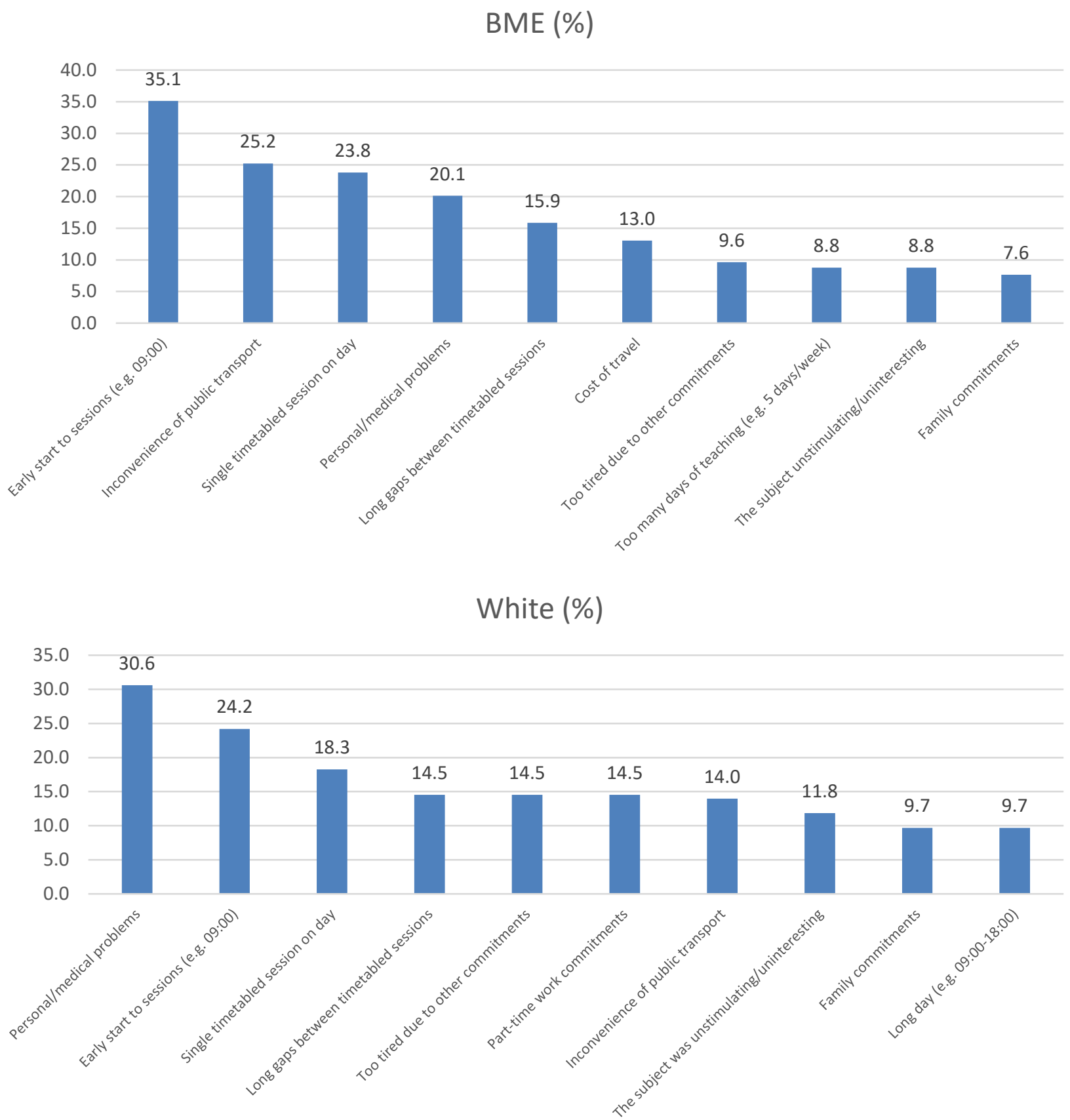

Figure 6 Prioritised reasons given by students for not attending timetable sessions (top: BME; bottom: White). Data labels represent percentage of students selecting option.

'the timetable works efficiently for me' being $77.6 \%$ and $70.4 \%$, respectively. Students who travelled by public bus (satisfaction was $61.9 \%)$, motorcycle or car $(58.5 \%)$ and particularly for those who travelled by train or tube was only $54.6 \%$. The later three modes of transport, which made up $57 \%$ of our student study population were all associated with much poorer satisfaction scores for 'the timetable works efficiently for me' $\left(\chi^{2}, 21.32, d f=10, p=\right.$ $0.017)$.

\section{Student barriers and enablers to the timetable}

Participants were asked to select from a list of 26 potential barriers those that prevented them from attending their timetabled sessions and to prioritise their top three. From this, we produced a top 10 of the priority barriers, producing a list for both BME and White student groups (Figure 6). Eight of the top ten barriers were common to both BME and White students, where early starts to sessions 


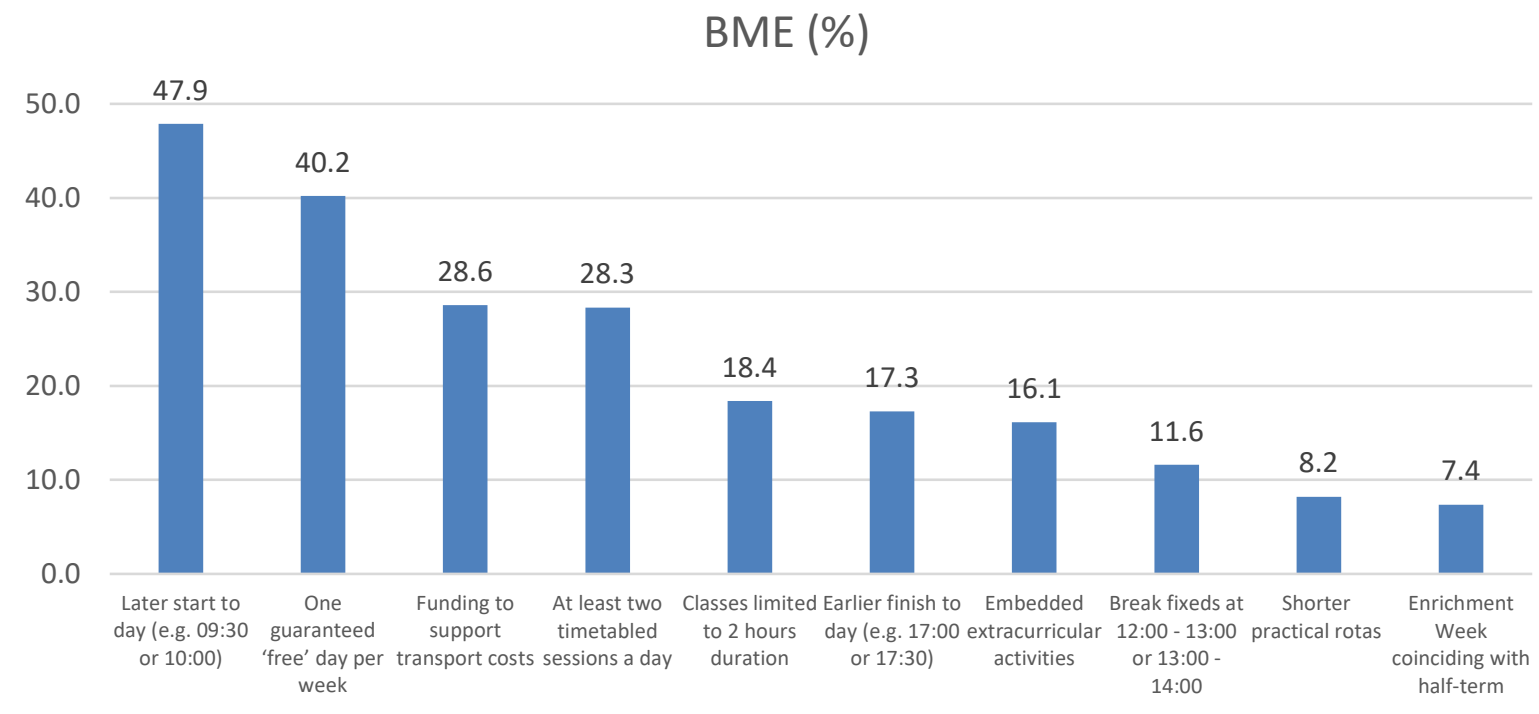

White (\%)

50.0

41.9

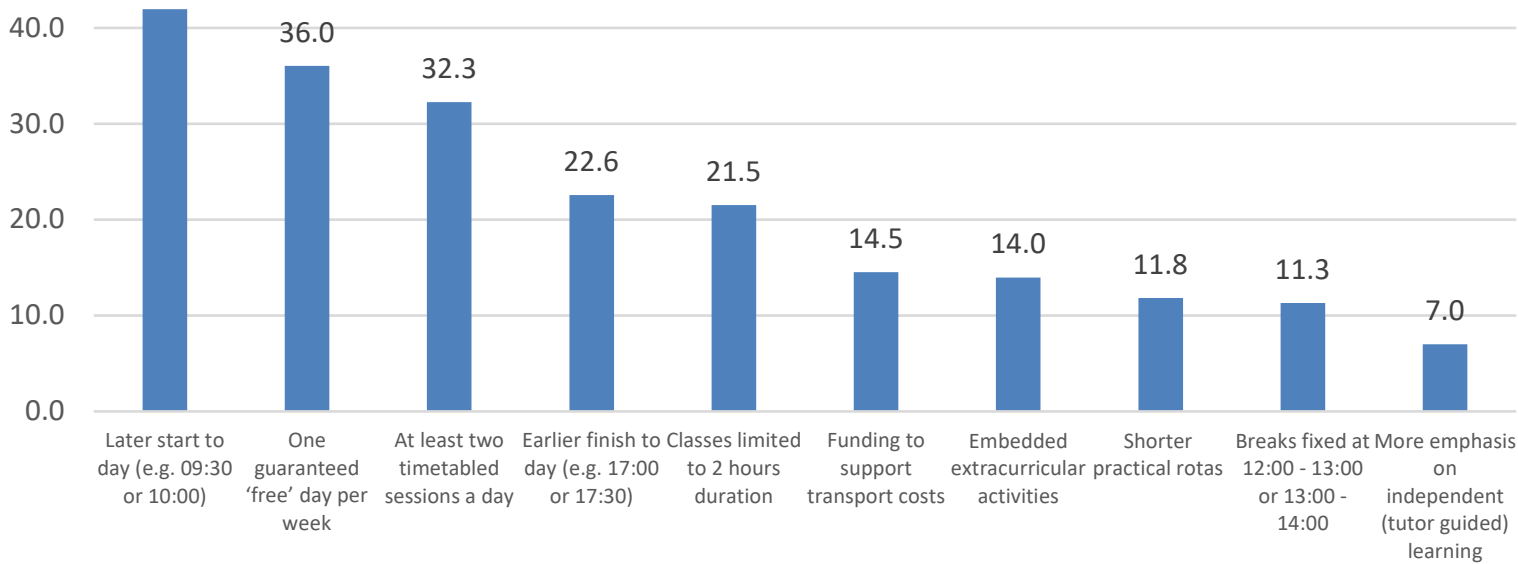

Figure 7 Prioritised reasons given by students for improving the timetable (top:

BME; bottom: White). Data labels represent percentage of students selecting option.

(e.g., 09.00) and single timetabled sessions on a day were in the top three for both groups. For BME students, the impact, inconvenience and cost of public transport were greater priorities than those for White students. Personal and medical reasons and having long gaps between timetabled sessions were all in the top five for both groups (Figure 6).

When asked, to elaborate on the barriers faced, some of the typical statements made by students in the focus group were recorded.

"There was no commute when at school, there is now, and it can be stressful"
"The commute takes so long, that's a big thing it's hard to schedule too"

"Commuting if you live at home, 2 hours or more is hard"

"Commutes much longer, can have just one lecture opposed to a routine 6 hours a day at school. Can seem pointless coming in for such a short amount of time"

"With school you know what you're getting, there is a routine. You get more out of a school day and more contact hours with staff. The commute is much longer than school" 


\section{"It's not that I thought a commute would work, I came through clearing and couldn't get a place in halls"}

"Plus $11 / 2$ half hour travel to and from university so 3 hours extra wasted in the day. Results in when you get home you are tired, and you struggle to work"

\section{"There is nowhere for us to go between gaps in lectures and we just spend our time wandering around" \\ "It cost me £25 to travel peak time for a one-hour lecture"}

To counter the barriers faced, we asked students to consider and prioritise from a list of 14 , the actions that could be taken to improve their timetables (Figure 7). The individual enablers ranked between BME and White students were very similar, where the top two priorities for both groups were 'later starts to the university day (e.g., 09.30 or 10.00 )' and 'one guaranteed free day per week'. Students also wanted to 'ensure there was at least two timetabled sessions in a day' and have 'classes limited to 2 hours duration'. In addition, for BME students funding to support transport costs was a priority.

\section{Discussion}

There can often be assumptions that the UK university experience is characterised by young people moving a long way from home for the first time (Donnelly \& Gamso, 2018). Nonetheless, although this tends to be true of the older research-intensive establishments, many post-1992 universities and increasingly those in London have more regionally localised student populations that often do not move out of home and therefore commute (Donnelly \& Gamso, 2018). For students in these institutions, perceptions of their timetable and the impact of their commute can make big differences on their overall learning experience and the outcomes of student surveys (such as the National Student Survey). These perceptions are further underscored by enormous differences between ethnic and social groups, where students from ethnic backgrounds and lower socio-economic groups are more likely to live at home and attend post-1992 universities (Donnelly, 2018). Therefore, the impact of the timetable working efficiently or not becomes important especially for a London post-92 institution with a large ethnic community.

For this study, we were able to survey a significant portion of our school's student population, which has a high number of BME and also those of mature students. Overall, agreement to 'the timetable works efficiently for me' (Q16 NSS) from this survey was $64.2 \%$ with no significant differences found for ethnicity, gender or age. Nonetheless, there were significant differences between student opinions at level 4 compared to those at level 5 and 6 with much higher satisfaction rates at level 4. We do not have a comparator for level 4 (as our university does not conduct a general survey at this level), but at level 5, our university survey has produced similarly poorer satisfaction rates for 'the timetable working efficiently for me' $(52.2 \%, 2018 ; 56.4 \%, 2019$; and $42.6 \%, 2020)$. In fact, it has been consistently the most poorly answered question in the survey in terms of student satisfaction. It is likely that many level 4 students will be experiencing a timetable with fewer timetabled hours and less routine than they had at school or college (Parker et al., 2017). This extra freedom may be viewed as positive by many transitioning students along with the fact that many will be living in student halls of residence in reasonable proximity to campus. In addition, the halls of residence are directly linked to campus by a dedicate university bus service. Students who used the university bus had the greatest positive satisfaction rates for 'the timetable works efficiently for me' $(77.6 \%)$, where $82 \%$ of the respondents using this bus service were level 4 students. The ability for students in halls of residence to meet and travel together likely adds a more collegial feel to sharing their scheduling experience.

Our results, at level 5 and 6 , demonstrate we still have some way to go to achieving a student-centred timetable. Some of the challenges in achieving this are highlighted in the disparate living and travel arrangements of our diverse student body. It is clear, there is not a uniform playing field particularly between different ethnic groups and ages. Students from ethnic backgrounds on average travelled 
double the distance of their White counterparts to get to university. Correspondingly, this was mirrored by longer travel times, which also impacted the modes of transport used. The majority of White (male $77.5 \%$ and female $73.1 \%$ ) students lived within 0 to 30 minutes from the university compared to BME (male $46.7 \%$ and female $39 \%$ ) students. Longer journey times were also found for mature students including those who are White. The overlap in some BME and mature student characteristics has been previously reported by research for the Department of Business, Innovation and Skills (Artess et al., 2014).

Our own preliminary evidence (not presented here in granular detail) also indicates that even within the BME group, there are acute differences, showing that Pakistani, Bangladeshi, Black Caribbean and Arab students are more effected by longer travel times than Chinese and White mixed-race students, who tended to have shorter travel times to university. This is set against a backdrop of very distinct year on year ethnic profiles for individual courses, which adds further complexities for course teams in considering course specific timetables. Furthermore, we provide evidence of distinct and established travel patterns for both BME and White students across each of the levels of study. This implies that once commuting arrangements have been established, they appear to remain quite static, that is BME students do not move nearer to the university in subsequent years of study to avoid commuting. These differentials between BME, mature and White students are likely to affect overall engagement, learning experiences and social life (Morris, 2018), especially if many BME and mature students have to schedule on average around an additional two hours each day on return travel to university. Our separate analysis of Kingston University demographic admissions data supports the notion that the vast majority of our BME students are likely to be short, medium, and long-distance commuters, while many of our White students are likely to be medium distance movers (Donnelly \& Gamsu, 2018).

Longer distances and travel times are not those than can be simply walked or taken by the university bus service, and therefore these journeys tend to rely more on public transport.
Furthermore, especially for journeys across large cities such as London, longer travel journeys (even over relatively short distances) are often more complex in their nature and can involve several changes (Page, 2018) leading to more opportunities for delays and stress especially at peak travel times (Thomas, 2019). Particularly, poignant is that students travelling by rail (mainline and tube) had the lowest satisfaction responses to timetable satisfaction. Travel by train is likely to be associated with longer travel distances and in south-west London, travel to Kingston University is primarily based on a single main arterial route. Any disruptions to this route often impacted the whole community of students who travel by train, which from our study would affect approximately one in three students. Mode of transport and travel times all impacted on student satisfaction with their timetables.

We found a direct negative correlation with travel times and student satisfaction with their timetables (question 16 of the National Student Survey). The relationship to travel time was also significant for BME vs White students (but not for gender or age), although we believe the true difference is a reflection of commuting status rather than ethnicity (being simply dictated by more BME students living further away from the university than White students). Such an outcome for question 16 of the NSS has the potential to disadvantage those students and institutions that have a higher proportion of commuting students; and especially in larger cities, such as London, which have more complex travel networks. Indeed, a London effect in the Teaching Excellence Framework (TEF) results has been previously reported, where students in the capital gave noticeably poorer satisfaction scores (Buckley-Irvine, 2017). In interpreting a reason for this, Buckley-Irvine (2017) suggested a 'contact hours' effect that may be greater in London, with students feeling more disgruntled about relatively low contact hours when located far from their campus.

To review, if there was a London effect for question 16 of the NSS, we performed an analyse of the publicly available NSS data from 2018 to 2020 (Office for Students, 2020) by comparing the overall percentage satisfaction of the 23 institutions within the Greater London area to the 107 across the rest of the United 
Kingdom. In London, the mean satisfaction rates for question 16 were $75 \%, 75.6 \%$ and $74.2 \%$ compared to $78.7 \%, 78.3 \%$ and $77.8 \%$ for institutions outside of London for 2018, 2019 and 2020, respectively. On average, London institutions consistently scored over $3 \%$ lower, which was found to be a significant difference each year $(p<0.05)$ compared to those institutes outside London.

In terms of meeting expectations in contact hours, we found around $20 \%$ of our students reported lower than expected hours (which was independent of age, ethnicity and level of study). Nonetheless, delving deeper, it was revealed those students with the shortest travel times ( 0 to 30 minutes) were the most likely to feel they were getting lower than expected contact hours. Perhaps, unsurprisingly the converse was also true for those students with the longest travel times stating they had 'too much' hours (which happened to be mainly BME students). Thomas (2019) commented that some commuting students are surprised by the amount of time they were expected to be on campus. Of interest, a great majority of our students claimed they were attending $75-100 \%$ of their timetabled sessions, however, there was a significant number of White males admitting they skipped a greater number of their sessions. This may be part of a gender gap, where White males are less likely to commence university, be retained or attain as well (Woodfield \& Thomas, 2012).

Upon reviewing student barriers for not attending their timetabled sessions, we found that even given the disparate living and travel arrangements of our diverse student body there was much in common between the different student opinions, whether BME or White. Early starts to the day, single timetabled sessions on a day, personal and medical reasons, and long gaps between timetabled sessions were all high on the agenda. Where differences appeared, these were primarily concerned with the inconvenience of public transport and related costs (BME) or part-time work commitments (White). In the same manner, prioritised reasons for improving the timetable were centred around ensuring a later start to the day, one guarantee free day of the week, having at least two timetabled sessions on a day and not having teaching sessions longer than two hours. In many ways, these common overarching priorities lend themselves to developing an all-inclusive timetabling strategy. Nevertheless, even having clearly defined priorities parallels the logistical need of how to deliver such a significant number of diverse timetabled activities across the whole estate with its many complexities. There remain numerous constraints to consider including staff availability and potential timetabling clashes for both staff and students that all need to be considered.

If there is one constructive outcome of the current COVID-19 pandemic for education, it is that it has acted as a positive disruptor. Not only has it 'temporarily' reduced the need for most students to commute but opened up new opportunities to review our learning and teaching approaches for learners who has not been able to commute. For the future, it will be important to find a new balance in applying the identified priorities and integrating the newly realised alternative COVID-19 teaching approaches to create more inclusive, flexible and blended learning environments. This may then finally allow us to achieve the ultimate student-centred timetable. One thing for sure is that the current necessities have allowed us to be bolder in making changes and it will be very difficult for such changes not to become the new 'normal'.

\section{References}

Artess, J., McCulloch, A., Mok, P. (2014) Learning from Futuretrack: studying and living at home. BIS Research Paper 167 London: Department for Business, Innovation and Skills. Available at; https://www.gov.uk/government/publications/l earning-from-futuretrack-studying-and-livingat-home

Buckley-Irvine, N. (2017) TEF results making sense of the London effect.

WONKHE. Available at: https://wonkhe.com/blogs/tef-results-makingsense-of-the-london-effect/

Donnelly, M. (2018) Unequal mobilities. WONKHE. Available at: https://wonkhe.com/blogs/unequal-mobilities/ 
Donnelly, M. \& Gamsu, S. (2018) Home and

Away. Social, ethnic and spatial inequalities in student mobility. The Sutton Trust. United Kingdom. Available at:

https://www.suttontrust.com/wpcontent/uploads/2019/12/Home and away FI NAL.pdf

Morgan-Tamosunas, R. (2012). Dundee tops THE Student Experience Survey as fees put focus on 'value for money'. Times Higher Education. United Kingdom. Available at: https://www.timeshighereducation.com/news/ dundee- tops-the-student-experience-surveyas-fees-put-focus-on-value-formoney/419771.article

Morris, D. (2018) Students who commute to university are getting a raw deal. The Guardian. Available at:

https://www.theguardian.com/education/2018/ dec/13/students-who-commute-to-universityare-getting-a-raw-deal

Office for Students. (2020) get the NSS data Office for Students. Available at: https://www.officeforstudents.org.uk/adviceand-guidance/student-information-anddata/national-student-survey-nss/get-the-nssdata/

Page, N. (2018) The 07.03 from Watford High Street to Dr Page's 9 o'clock lipid lecture. In Evolving molecular bioscience education. Available at: https://eprints.kingston.ac.uk/id/eprint/41262/

Parker, H., Hughes, A., Marsh, C., Ahmed, S., Cannon, J., Taylor-Steeds, E., Jones, L. \& Page, N. (2017) Understanding the different challenges facing students in transitioning to university particularly with a focus on ethnicity. New Directions in the Teaching of Physical Sciences, 12, ISSN (online) 2051-3615. DOI: 10.29311/ndtps.v0i12.2450

Southall, J., Wason, H. \& Avery B. (2016) Non-traditional, commuter students and their transition to Higher Education - a synthesis of recent literature to enhance understanding of their needs. Student Engagement and Experience Journal, 5, 1-15. DOI: 10.7190/seej.v4i1.128
The Quality Assurance Agency for Higher Education (2014) What students think of their higher education. Analysis of student submissions to the quality assurance agency for higher education 2012-3. The Quality Assurance Agency for Higher Education. United Kingdom. Available at: www.qaa.ac.uk

Thomas, L. (2019) Commuter students in London. London Higher: Supporting Higher Education in London. Available at: https://www.londonhigher.ac.uk/news/reportpublication-commuter-students-in-london/

Thomas, L. \& Jones, R. (2017) Student engagement in the context of commuter students. The Student Engagement Partnership. London. Available at: https://www.lizthomasassociates.co.uk/project s/2018/Commuter\%20student\%20engagemen t.pdf

Webb, O., Wyness, L. \& Cotton, D. (2017) Enhancing access, retention, attainment and progression in higher education. A review of the literature showing demonstrable impact. Higher Education Academy. United Kingdom. Available at:

https://www.heacademy.ac.uk/system/files/res ources/enhancing access retention attainme nt and progression in higher education.pdf

Woodfield, R. \& Thomas, L. (2012) Male students: engagement with academic and pastoral support services. Equality Challenge Unit. London. Available at: https://www.ecu.ac.uk/wpcontent/uploads/external/male-studentsengagement-with-academic-and-pastoralsupport-services.pdf 